\title{
ANALISIS SOSIO-EKONOMIS UNTUK EVALUASI LAHAN PERMUKIMAN
}

\author{
Oleb : Su Ritobardoyo
}

\begin{abstract}
A problem which commonly exist take a shape in the discrepancy of physical land suitability and socio-economic suitability. Another problem which also appear, is in the difference delineation of boundary of land unit. From physical point of view the analysis is based on physical boundary, whereas the available socio-economic data employs merely an administrative boundary. The available data contribute also to the mentioned problem. The data of physical aspect has a more quantitative character, in comparison to the data of socio-economic that has a more qualitative character. Those differences lead to the problem on analysis. In this light, there is a need to quantify the socio-economic data in order to facilitate techniques for delineation of land unit and technique for quantitative analysis. The study comes out wibt the result that the village administrative unit can be well exerted for socio-economic land unit, although physical landa unit has adetail variation. The use of secondary data of Potensi Desa either in rural area or in urban area, from socio-economic aspect is reasonabley representative to support settlement land resources evaluation of rural as well as urban.
\end{abstract}

\section{INTISARI}

Masalah yang sering terjadi dalam evaluasi sumberdaya lahan permukiman, adalab ketidakseimbangan antara kesesuaian secara fisik laban, dengan kesesuaian secara sosio-ekonomis. Di samping itu permasalaban yang muncul, adalab dalam penentuan batas yang berbeda ada satuan laban. Satuan laban secara fisik menggunakan dasar batas fisik, sedangkan secara sosio-ekonomis mengikuti satuan luasan mendasarkan pada batas administratif. Demikian juga adanya perbedaan ketersediaan data, yakni data aspek fisik bersifat kuantitatif sedangkan data sosio ekonomis bersifat kualitatif, sebingga merupakan masalah dalam analisisnya. Oleh karenanya, didalam teknik penentuan batas satuan laban, serta teknik analisis kuantitatif data sosio-ekonomis memerlukan teknik kuantifikasi data kualitatif. Hasil kajian ini menunjukkan bahwa penggunaan batas administratif desa untuk satuan sosio-eknomis lahan dapat digunakan secara tepat, walaupun satuan laban secara fisik bervariasi secara rinci. Penggunaan data sekunder potensi desa, baik di pedesaan ataupun perkotaan dari aspek sosio-eknomis cukup representatif untuk mendukung evaluasi sumberdaya lahan permukiman baik pedesaan maunpun perkotaan.

\section{Pengentar}

Variasi sumberdaya lahan sangat besar. Besarnya variasi tersebut bergan- tung pada faktor lingkungan fisik (alami dan binaan), biotik, maupun lingkungan manusia. Oleh karenanya, berbagai 
informasi untuk menentukan pemanfaatan sumberdaya lahan, beserta informasi keterbatasan-keterbatasannya sangat diperlukan. Setiap faktor memiliki peranan dalam pemanfaatan lahan. Namun, derajad kepentingannya bergantung pada tujuan kegiatan, apakah untuk evaluasi, perencanaan pengembangan, atau untuk pengelolaan penggunaan lahan. Di samping itu, tingkat kepentingannya tergantung pada bentuk penggunaan lahan. Berbagai bentuk penggunaan lahan dapat disebutkan misalnya lahan untuk pertanian, kehutanan, pertambangan, pertenakan, perikanan, industri, pertambangan, rekreasi (wisata), dan lahan permukiman.

Dalam perencanaan penggunaan lahan ini, diperlukan evaluasi sumberdaya lahan sebagai dasar perencanaannya. Hal ini disebabkan dalam evaluasi mempertimbangkan berbagai kemungkinan penggunaan, dan pembahasan faktor-faktor pembatas maupun pendukung, serta menterjemahkan informasiinformasi yang cukup banyak dari lahan ke dalam bentuk bentuk yang dapat digunakan, baik oleh praktisi maupun pakar yang mempertanyakan mungkin atau tidaknya penggunaan lahan untuk tujuan tertentu. Namun demikian, masalah yang sering dihadapi hasil evaluasi sumberdaya lahan secara fisik menunjukkan kesesuaian untuk salah satu bentuk penggunaan lahan tertentu, tetapi secara sosio-ekonomis kadangkala masih belum terdapat kesesuaian.

Dalam rangka mengevaluasi sumberdaya lahan untuk perrnukiman, pada dasarnya mencakup dua analisis yakni analisis lahan permukiman dari aspek fisik, dan analisis lahan permukiman dari aspek sosi-ekonomis. Namun demikian, permasalahan yang muncul adalah dalam penentuan satuan analisis lahan secara fisik menggunakan dasar batas fisik, sedangkan ketersediaan data sosioekonomis mengikuti satuan areal yang mendasarkan pada batas administratif. Masalah lain yang sering timbul, adalah perbedaan ketersediaan data yakni data aspek fisik bersifat kuantitatif, sedangkan sebagian data sosio-ekonomis bersifat kualitatif. Oleh karenanya, pembahasan mengenai teknik penentuan batas satuan analisis, serta teknik kuantifikasi data sosio-eknomis dipandang cukup relevant, dan merupakan tujuan dari penulisan ini, terutama untuk mendukung teknik evaluasi sumberdaya lahan permukiman baik pedesaan maupun perkotaan.

Walaupun cukup banyak masalah yang dihadapi dalam analisis sosioeknomis lảhan, dalam pembahasan ini dibatasi pada uraian untuk menjawab pertanyaan-pertanyaan bahasan berikut:

- Faktor-faktor dan variabel sosioekonomis apa saja yang diperlukan untuk evaluasi sumberdaya lahan permukiman?

- Jenis data apa saja, dan dari mana sumber data sosio-ekonomis harus dikumpulkan?

- Bagaimana teknik kuantifikasi data kualitatif dan teknik analisis data tersebut?

Dengan pembahasan ini diharapkan mampu menunjukkan salah satu alternatif teknik analisis aspek sosio-ekonomis secara kuantitatif, sehingga dalam memadukan hasil analisis data sosioekonomis dengan hasil analisis data fisik lahan permukiman lebih mudah dilaksanakan.

\section{Identifikasi Satuan Lahan Permukiman}

Permukiman sebagai suatu ruang atau lahan terbentuk oleh unsur-unsur yang dipergunakan penduduk untuk bertempat tinggal dan menyelenggara- 
kan kehidupannya. Unsur-unsur tersebut:

lahan kerja (working opportunities), lahan transportasi dan komunikasi (circulations),

lahan perumahan (bousing),

- lahan recreasi ( recreation)

- lahan fasilitas lain untuk menunjang kehidupan (other living facilities)

Dalam hal ini satuan lahan permukiman mencakup berbagai bentuk penggunaan lahan yang dapat didelineasi atas dasar batas administratif, baik tingkat kecamantan, desa atau kalurahan.

Untuk skala yang lebih sempit (mikro) kajian permukiman menyoroti salah satu dari unsur permukiman secara rinci, terutama perumahan. Unit atau satuan analisis lebih menekankan pada lingkungan tempat tinggal baik kota ataupun desa. Komponen-komponen satuan lingkungan tempat tinggal dibatasi pada bangunan rumah, fasilitas bangunan rumah, sanitasi, lingkungan dalam pekarangan bangunan rumah dan di luarnya, serta aspek estetika dan arsitektural bangunan rumah. Dalam kaitannya dengan satuan lahan permukiman, jelas batas lebih rinci untuk setiap penggunaan lahan lebih mikro dalam skala sempit, seberapa luas untuk bangunan rumah, halaman, pekarangan (kebun), lahan fasilitas penunjang kehidupan rumah tangga dalam lahan pekarangan.

Satuan lingkungan permukiman bukan saja ditentukan oleh dukungan kompenen fisik, biotik, binaan, tetapi yang sangat menetukan adalah komponen manusia sebagai penghuni maupun kelembagaannya (pemerintah). Oleh karena itu, dalam menentukan kesesuaian lahan permukiman dari aspek sosioekonomis, perlu memperhatikan segala faktor terutama dalam hubungannya dengan manusia dan aktifitasnya yang memanfaatkan ruang (lahan). Dari beberapa pengertian konsepsional di atas, dalam usaha menggali informasi sosio-ekonomis kesesuaian lahan permukiman perlu diidentifikasi beberapa hal, disesuaikan dengan tujuan evaluasi lahan permukiman tersebut.

Secara umum faktor sosio-ekonomis yang perlu diperhatikan dalam kaitannya satuan lahan adalah secara administratif. Dikaitkan dengan satuan lahan secara fisik, dapat saja satu satuan lahan sosio-ekonomis meliput beberapa satuan lahan secara fisik, atau sebaliknya. Dalam hal ini ada beberapa cara untuk menyesuaikan kedua batas satuan lahan tersebut. Pertama, jika satuan lahan fisik meliput sebagian kecil ( $<50 \%$ luas) satuan lahan sosio-ekonomis, maka data sosio-ekonomis mengikuti satuan lahan sosio-ekonomis yang lebih dominan (luas). Kedua, jika satuan lahan fisik meliput sebagian besar (>50\%) satuan lahan sosio-ekonomis, maka data sosioekonomis langsung dapat mewakili unit lahan fisik tersebut. Ketiga, jika satuan lahan fisik meliputi lebih dari dua satuan lahan sosio-ekonomis, maka batas administratif sebaiknya digunakan sebagai pembagi satuan lahan fisik tersebut, sehingga satu satuan lahan fisik dengan karakteristik fisik sama dibedakan lagi atas dasar karakteristik sosio ekonomis yang berbeda.

\section{Faktor Sosio-Ekonomis Untuk Evaluasi Lahan}

Dalam hubungannya dengan satuan lahan, secara umum faktor sosial dan ekonomi yang perlu diperhatikan secara umum adalah:

a. kepadatan penduduk, mata pencaharian penduduk,

c. tingkat ketrampilan dan pengetahuan penduduk, 
d. persepsi dan nilai-nilai yang hidup di masyarakat terhadap pemanfaatan sumberdaya lahan.

e. tingkat pendapatan,

f. keterbukaan wilayah,

Identifikasi lebih rinci dari faktorfaktor tersebut dapat ditunjukkan pada penurunannya ke variabel-variabel yang dapat diukur secara kuantatif. Namun demikian untuk tujuan yang lebih terperinci, masih perlu untuk dimodifikasi disesuaikan dengan kondisi wilayah yang diteliti. Keenam faktor tersebut jika diturunkan ke variable sosio-ekonomis, beserta kuantifikasinya dapat ditunjukkan pada tabel 1. Mengingat jenis dan ukuran setiap variabel pada tabel tersebut, masih terdapat beberapa kelemahan antara lain belum menunjukkan gambaran jelas tentang satuan analisis, apakah individu atau kelompok. Pada beberapa jenis variabel dapat digali datanya dari individu, tetapi sebagian lagi dapat dari kelompok. Oleh karena nya, sebelum menganalis masih me merluan tahap penyesuaian, minimal penggabungan atau perhitungan ratarata dari unit individu untuk mewakili unit kelompok. Namun yang jelas, bahwa untuk data dari satuan kelompok tidak dapat digunakan secara satuan individu.

Alternatif lain dalam penentuan faktor sosio-ekonomi permukiman, yang secara sistematik dapat dilaksanakan dengan mempertimbangkan ketersediaan data sekunder, adalah menggunakan variabel-variabel sebagai indikator sosio-ekonomis. Faktor-faktor tersebut secara umum yang dapat diper- hitungkan dalam analisis adalah sebagai berikut.

a. Potensi Desa/Kelurahan (prasarana dan sarana).

b. Lingkungann Perumahhan (penghuni dan fasilitas rumah).

c. Kondisi Demografis (kependudukan dan sosio-budaya)

Faktor-faktor di atas dapat digali dari permukiman desa baik di perkotaan, maupun permukiman desa di pedesaan. Untuk menunjukkan contoh yang lebih rinci, dari ketiga variabel umum di atas dapat diturunkan menjadi 25 variabel bagi permukiman desa di kota, dan menjadi 27 variabel beserta ukuran kuantitatifnya.

\section{Jenis dan Sumber Data}

Secara umum, data sosio-eknomi lahan permukiman dapat dibedakan menjadi dua, yakni data primer dan data sekunder. Pemilihan jenis data yang akan digunakan dalam analisis tergantung pada sekala kajian, makro, meso, atau mikro. Di samping itu, juga tergantung pada tujuan pembahasannya. Tabel 2. di samping menunjukkan jenis variabel juga dapat langsung digunakan sebagai acuan data yang harus dikumpulkan. Jika ditinjau dari jenis variabel dan data dalam tabel tersebut, tampaknya masih dapat tercukupi dari sumber data yang tertuang dalam Monografi Desa atau Kalurahan. Jika demikian halnya maka data sekunder cukup memadai untuk tujuan analisis.

Jika sebagian dari variabel atau data tersebut tidak tersedia dalam Monografi Desa atau Kalurahan, dalam rencana analisis dikehendaki analisis mikro (rinci), maka diperlukan data primer, yang harus dikumpulkan dari Responden sebagai sumber datanya. Namun jika hanya dikehendaki analisis 
Tabel 1. Variabel Sosio - ekonomis Secara Umum

\begin{tabular}{|c|c|c|c|c|}
\hline \multirow{2}{*}{ NO. } & \multirow{2}{*}{ VARIABEL } & \multicolumn{3}{|c|}{ KLASIFIKASI } \\
\hline & & SKOR TINGGI ( 3 ) & SKOR SEDANG ( 2 ) & SKOR RENDAH ( 1 ) \\
\hline 1 & 2 & 3 & 4 & 5 \\
\hline 1. & $\begin{array}{l}\text { KE P A D A T A N } \\
\text { PENDUDUK }\end{array}$ & ) 550 JIWAHA & 350 - ( 550 JIWA-IA & ( 350 JIWAHA \\
\hline 2. & MATA PENCAHARIAN & $\begin{array}{l}55 \% \text { PENDUDUK } \\
\text { BEKERJA DI SEKTOR } \\
\text { TERTIER }\end{array}$ & $\begin{array}{l}55 \% \text { PENDUDUK } \\
\text { BEKERNA DI SEKTOR } \\
\text { SEKUNDER }\end{array}$ & $\begin{array}{l}55 \% \text { PENDUDUK } \\
\text { BEKERNA DI SEKTOR } \\
\text { PRIMER }\end{array}$ \\
\hline 3. & $\begin{array}{l}\text { KETRAMILAN DAN } \\
\text { PENGETAHUAN }\end{array}$ & $\begin{array}{l}\text { ) } 60 \% \text { PENDUDUK } \\
\text { BERPENDIDIKAN SD } \\
\text { KE ATAS }\end{array}$ & $\begin{array}{l}30 \%-60 \% \text { PENDUDUK } \\
\text { BERPENDIDIKAN SD } \\
\text { KE ATAS }\end{array}$ & $\begin{array}{l}\text { ( } 30 \% \text { PENDUDUK } \\
\text { BERPENDIDIKAN SD } \\
\text { KE ATAS }\end{array}$ \\
\hline 4. & $\begin{array}{l}\text { PERSEPSI: } \\
\text { PEMANFA A T AN } \\
\text { LAHAN }\end{array}$ & $\begin{array}{l}\text { SEBAGIAN BESAR } \\
\text { SESUAI DENGAN } \\
\text { BIOFISIK }\end{array}$ & $\begin{array}{l}\text { SEBAGIAN } \text { BESAR } \\
\text { TIDAK SESUAI } \\
\text { DENGAN BIOFISIK }\end{array}$ & $\begin{array}{l}\text { SAMA SEKALITIDAK } \\
\text { SESUAI DENGAN } \\
\text { BIOFISIK }\end{array}$ \\
\hline & $\begin{array}{l}\text { KONSERVASI TANAH } \\
\text { DAN AIR }\end{array}$ & $\begin{array}{l}\text { PEMBUATANTERAS + } \\
\text { PENGUAT }\end{array}$ & $\begin{array}{l}\text { PEMBUATAN TERAS } \\
\text { TANPA PENGUAT }\end{array}$ & $\begin{array}{l}\text { TANPAPEMBUATAN } \\
\text { TERAS }\end{array}$ \\
\hline 5. & $\begin{array}{l}\text { NILAI DALAM } \\
\text { HUBUNG ANNYA } \\
\text { DENGAN LAHAN }\end{array}$ & $\begin{array}{l}\text { LAHAN BERNILAI } \\
\text { SOSIAL BUDYA }\end{array}$ & $\begin{array}{l}\text { LAHAN BERNILAI } \\
\text { UNTUKKEPENTINGAN } \\
\text { UMUM }\end{array}$ & $\begin{array}{l}\text { LAHAN BERNILAI } \\
\text { EKONOMIS }\end{array}$ \\
\hline 6. & $\begin{array}{l}\text { PENDAPATAN PER- } \\
\text { KAPITA (KG/TAHUN) }\end{array}$ & $\geqslant 360$ & $240-(360$ & $<240$ \\
\hline 7. & $\begin{array}{l}\text { KETERBUKAAN } \\
\text { WILAYAH }\end{array}$ & $\begin{array}{l}\text { DILEWATI JALAN } \\
\text { ASPAL }\end{array}$ & DILEWATIJALANBATU & $\begin{array}{l}\text { DILEWATI JALAN } \\
\text { TANAH }\end{array}$ \\
\hline
\end{tabular}


meso atau makro, dapat digunakan data yang tersedia saja untuk dianalisis, sedangkan variabel yang tidak tersedia datanya dapat ditinggalkan, sejauh tujuan secara umum dari analisis masih dapat terpenuhi.

Tabel 2 Jenis variabel, Data, dan Klasifikasi Data Sosio-eknomi Lahan Permukiman Desa/Kota

\section{KLASIFIKASI DAN ANALISIS DATA}

Seperti telah dikemukakan satuan analisis untuk data sosio-ekonomis pada umumnya unit administratif. Satuan ini dapat menggunakan tingkat kecamatan, atau tingkat desa dan atau kalurahan. Jika dikehendaki secara rinci dapat menggunakan satuan administratif kampung, RW, RT, bahkan rumah tangga. Tentu saja unit analisis kampung sampai rumah tangga, dalam pengumpulan datanya diperlukan wawancara untuk memperoleh data primer. Dalam contoh di atas (Tabel 2) satuan analisis dapat menggunakan batas administratif kecamatan, ataupun desa (kalurahan).

Atas dasar kedua puluh lima (25) variabel terukur (data) untuk desa perkotaan, dan keduapuluh tujuh (27) variabel terukur untuk desa di pedesaan (Tabel 2.), perlu dianalisis untuk dapat digunakan untuk evaluasi kesesuaian sosio-ekonomis lahan. Mengingat data sosio-ekonomis lebih banyak bersifat kualitatif, maka untuk kemudahan menentukan kesimpulan perlu dikuantifikkasi. Kuantifikasi data kualitatif dilakukan secara empiris, dengan mendasar asumsi-asumsi tertentu.

Dalam kuantifikasi data ini digunakan sistem penilaian menggunakan skor tertentu terhadap setiap ukuran variabel. Unntuk mengetahui ukuran tinggi- rendahnya kelas kesesuaian sosio-ekonomi setiap daerah digunakan nilai skor total, perdesa atau per kecamatan. Skor total tersebut selanjutnya diklasifikasi, agar diperoleh jenjang tinggi-rendahnya nilai kelas kesesuaian. Penyusunan kelas kesesuaian dapat didasarkan pada rumus yang sederhana, atau dapat pula menggunakan rumus statistik.

Cara klasifikasi yang paling mudah menggunakan rumus-rumus berikut:

\section{a. Menghitung Innterval Kelas}

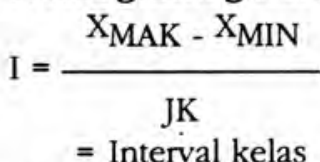

I $=$ Interval kelas

$\mathrm{X}_{\text {MAKS }}=$ Skor total maksimum permukiman desa di suatu wilayah

$\mathrm{X}_{\mathrm{MIN}}=$ Skor total minimum permukiman desa di suatu wilayah

$\mathrm{JK} \quad=$ Jumlah kelas yang dikehendaki (lima kelas misalnya)

\section{b. Penentuan Kelas Kesesuaian}

Sebagai contoh aplikatif dari data potensi desa di seluruh kabr zaten Kulonprogo tahun 1990 dapat ditunjukkan pada tabel 4. Tabel tersebut memperlihatkan bahwa kabupaten Kulonprogo terdiri dari 12 satuan admistratif kecamatan. Jika satuan analisis dikehendaki menggunakan admistratif desa, maka dapat dibagi menjadi 88 satuan desa. Di samping itu, tabel menunjukkan hasil perthitungan skor yang cukup rinci dari tiga komponen yakni potensi desa, perumahan dan lingkungan, dan kondisi demografis, serta skor total untuk kesesuaian sosio-eknomi. Nilai atau skor total tertinggi desa di Kabupaten Kulonprogo sebesar 80 (desa Wa- 
Tabel 2. Jenis Variabel, Data, dan Klasifikasi Data

Sosio-ekonomi Lahan Permukiman Desa / Kota

\begin{tabular}{|c|c|c|c|c|c|c|c|}
\hline \multirow{2}{*}{ NO. } & \multirow{2}{*}{ VARIABEL } & \multicolumn{6}{|c|}{ KLASIFIKASI } \\
\hline & & SKOR TINGGI & & SKOR SEDANG & & SKOR RENDAH & \\
\hline 1 & 2 & 3 & & 4 & & 5 & \\
\hline I. & POTENSI DESA & $\ldots 30$ & & $\ldots$ & & $\ldots 10$ & 10 \\
\hline 1. & TIPE LKMD & TIPE 3 & 3 & TIPE $1 / 2$ & 2 & TIPE O & 1 \\
\hline 2. & JALAN UTAMA DESA & ASPAL & 3 & DIPERKERAS & 2 & TANAH & 1 \\
\hline 3. & $\begin{array}{l}\text { SEBAGIAN PENDUDUK } \\
\text { BERGANTUNG PADA } \\
\text { POTENSI }\end{array}$ & $\begin{array}{l}\text { PERDAGANGAN JASA } \\
\text { DLL }\end{array}$ & & $\begin{array}{l}\text { INDUSTRI /KERA- } \\
\text { JINAN }\end{array}$ & 2 & PERTANIAN & 1 \\
\hline 4. & $\begin{array}{l}\text { RATA2 TANAH PERTAN. } \\
\text { YG. DIUSAHAKAN/RT } \\
\text { TANI UNTUK PERTANIAN }\end{array}$ & $1 \mathrm{HA}$ & 3 & $0,5-1 \mathrm{HA}$ & 2 & $(0,5 \mathrm{HA}$ & 1 \\
\hline 5. & $\begin{array}{l}\text { JARAKDARIKELURAHAN } \\
\text { KEIBUKOTAKECAMATAN }\end{array}$ & $0.5 \mathrm{KM}$ & 3 & $6.9 \mathrm{KM}$ & 2 & ) $10 \mathrm{KM} \mathrm{KM}$ & 1 \\
\hline 6. & FASILITAS PENDIDIKAN & S/D SLTA KEATAS & & $\begin{array}{l}\text { S/D SLTP } 2 \\
\text { PUSKESMAS }\end{array}$ & 2 & $\begin{array}{l}\text { S/D SD PUSKESMAS } \\
\text { PEMBANTU }\end{array}$ & 1 \\
\hline 7. & FASILITAS KESEHATAN & POLIKLINIK KE ATAS 3 & & & & & \\
\hline 8. & $\begin{array}{l}\text { TENAGA KESEHATAN } \\
\text { TINGGAL DI DESA }\end{array}$ & DOKTER & & PARAMEDIS & 2 & DUKUN BAYI & 1 \\
\hline 9. & SARANA KOMUNIKASI & $\begin{array}{l}\text { TELEPON TERPASANG } \\
\text { /UMUM }\end{array}$ & & KANTOR POS & 2 & TIDAK ADA SARANA 1 & 1 \\
\hline 10. & PASAR & $\begin{array}{l}\text { BANGUNAN PERMA- } \\
\text { NEN/SEMI PERMANEN } \\
3\end{array}$ & & $\begin{array}{l}\text { KIOS / KELOMPOK } \\
\text { PERTOKOAN }\end{array}$ & 2 & $\begin{array}{l}\text { TANPA BANGUNAN } \\
\text { PERMANEN/SEMII } \\
\text { PERMANEN }\end{array}$ & 1 \\
\hline II. & $\begin{array}{l}\text { PERUMAHAN \& LINGKU. } \\
\text { NGAN }\end{array}$ & $\ldots \ldots \ldots \ldots \ldots \ldots 27$ & & n.w. & & n.w. & \\
\hline 11. & $\begin{array}{l}\text { KEPADATAN PENDUDUK } \\
\text { PER KM }\end{array}$ & 0.200 JIWA 4 & 4 & 201 - 299 JIWA & 3 & ) 300 JIWA & 1 \\
\hline 12. & SUMBER AIR MINUM & PAM. POMPA LISTRIK 3 & & $\begin{array}{l}\text { SUMUR POMPA } \\
\text { MATA AIR }\end{array}$ & 2 & $\begin{array}{l}\text { AIR HUJAN, SUNGAI } \\
\text { MUNTABERVDEMAM }\end{array}$ & 1 \\
\hline 13. & $\begin{array}{l}\text { WABAH PENYAKIT } \\
\text { SELAMA 1 TH. } \\
\text { TERAKHIR }\end{array}$ & $\begin{array}{l}\text { TIDAK ADA } \\
\text { WABAH }\end{array}$ & & $\begin{array}{l}\text { SELAIN MUNTABER } \\
\text { /DEMAM BERDA- } \\
\text { RAH PALING SEDIKIT } \\
\text { IX }\end{array}$ & 2 & $\begin{array}{l}\text { BERDARAH PALING } \\
\text { SEDIKIT IX }\end{array}$ & 0 \\
\hline 14. & BAHAN BAKAR & LISTRIK / GAS & & MINYAK TANAH & 2 & KAYU BAKAR & 1 \\
\hline 15. & PEMBUANGAN SAMPAH & $\begin{array}{l}\text { TEMPAT SAMPAH } \\
\text { DIANGKUT }\end{array}$ & 3 & KE DALAM LUBANG & 2 & KE KALI/LAINNYA & 1 \\
\hline 16. & JAMBAN & SENDIRI & 3 & BERSAMA-SAMA & 2 & LAINNYA & 1 \\
\hline 17. & PENERANGAN & LISTRIK PLN & 3 & LISTRIKNON PLN & 2 & LAINNYA / TAK ADA & 1 \\
\hline 18. & $\begin{array}{l}\text { RASIO BANYAKNYA } \\
\text { TEMPAT IBADAH PER } \\
1000 \text { PENDUDUK }\end{array}$ & ) $5 / 1000$ & 3 & $(2-5) / 1000$ & 2 & ) $1 / 1000$ & 1 \\
\hline
\end{tabular}

Forum Geografi No. 12 Th. VII / J u 1 i 1993 


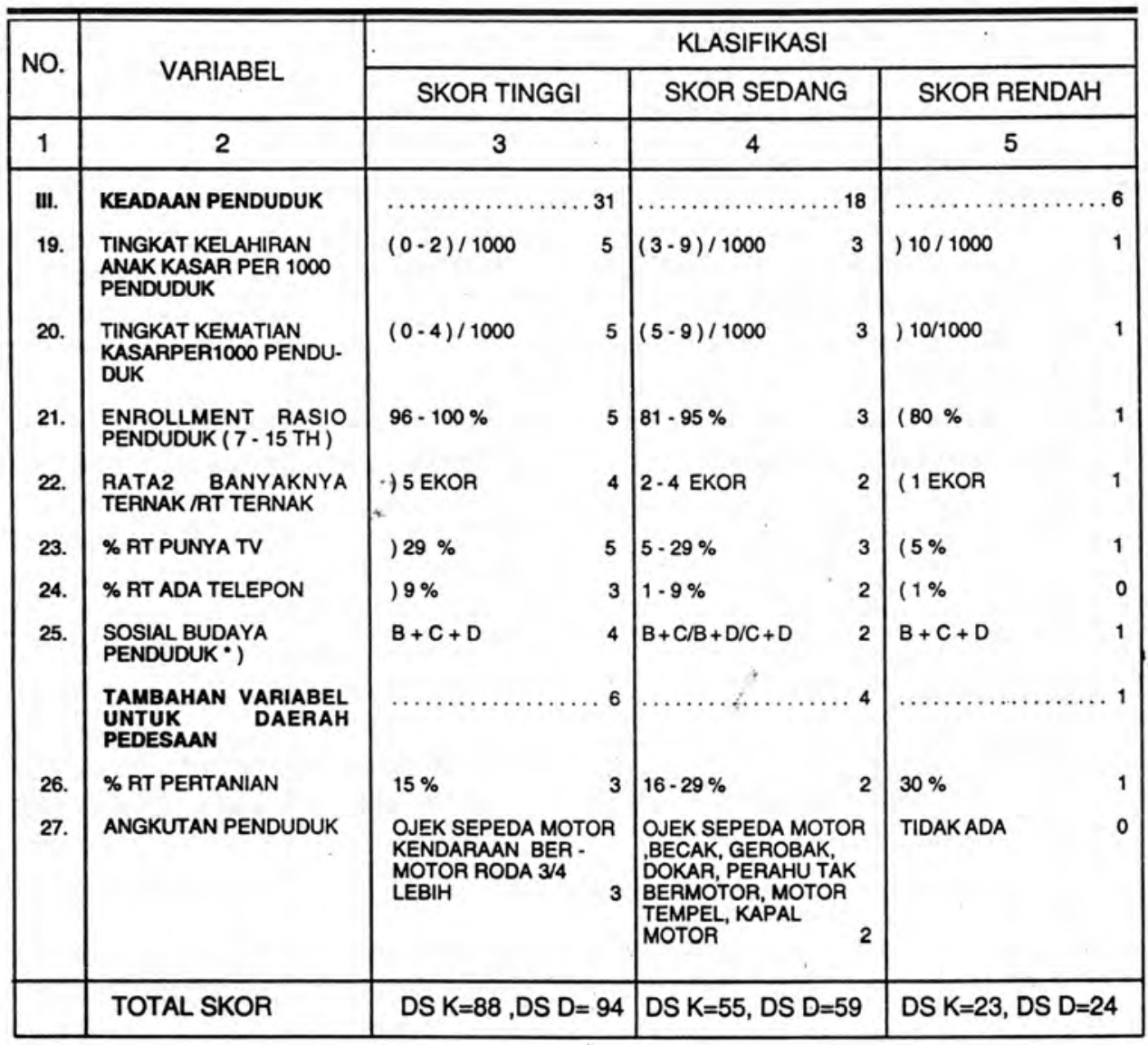

Sumber : BPS, 1992

KETERANGAN :

DS $K=$ DES $\Lambda$ PERKOTAAN; DS D = DESA PEDESAAN

$\mathrm{B}=8$ JENIS FASILITAS DAN KEGIATAN OLAH RAGA (SEPAK BOLA, VOLI, BADMINTON, PINGPONG, BASKET, TENIS, RENANG, LAINNYA).

$C=5$ ORGANISASI SOSIAL (GUDEP PRAMUKA, PANTI ASUHAN, PANTI JOMPO, PANTI CACAT, USAHA KESEJAHTERAAN LAIN).

D = 7 JENIS REKREASI DAN KESENIAN ( SANDIWARA, WAYANG ORANG, KETHOPRAK, TARITARIAN, MUSIK, DAN KARAWITAN).

RUMUS RI.ASIFIRASI :

$I=\frac{X_{\text {MAKS }}-X_{\text {MIN }}}{J K}$

I $\quad=$ INTERVAL KELAS

$\mathrm{X}_{\text {MAKS }}=$ SKOR TOTAL, TERTINGGI PERMUKIMAN DESA DI SUATU WILAYAH

X

$\mathrm{JK}^{\mathrm{IN}}$ = JUMLAH KELAS YANG DIKEHENDAKI (DALAM HAL INI LIMA KELAS) 
tes), sedangkan yang terendah sebesar 42 (desa Kalirejo).

Jika rumus a. di atas digunakan untuk menentukan lima kelas kesesuaian, maka dapat diperoleh besarnya interval kelas:

$$
\frac{80-42}{5}=7,6
$$

Dengan demikian dapat disusun klasifikasi kesesuaian sosio-ekonomi untuk lahan permukiman (untuk prioritas pengembangan), dengan batasbatas nilai kuantitatif sebagai berikut.

Menggunakann kelas-kelas yang telah disusun tersebut kesesuaian sosio-ekonomi lahan permukiman setiap desa di kabupaten Kulonprogo dapat ditentukan. Dalam hal ini tinggal memberikan angka kelas di belakang angka total skor pada setiap desa (tabel 5). Di muka sudah disebutkan bahwa penilaian ini untuk satuan tingkat desa. Oleh karenanya jika dikehendaki satuan tingkat kecamatan, secara mudah tinggal mencari perata nilai skor total pada tingkat kecamatan, dibagi dengan jumlah daerah desa di setiap kecamatan. Hasil pembagian tersebut dibandingkan dengan nilai kesesuaian pada tabel 4, sehingga dapat diketahui untuk kecamatan tertentu terletak pada kelas kesesuaian tertentu.

\section{Kesesuaian Sosio-ekonomi dan Fisik Lahan Permukiman}

Perhatian yang perlu ditekankan pada penggunaan data sosio-ekonomis ada beberapa hal. Pertama, sifat data yang selalu berubah setiap saat (dinamik). Data di atas adalah data tahun 1990, sehingga untuk diaplikasikan saat ini masih harus dicek kembali atas dasar data sosio-ekonomis saat terakhir (pada saat penelitian). Hal ini penting untuk mempertahankan validitas data yang dapat mewakili gambaran kondisi sosio-ekonomis saat penelitian. Dengan demikian, kondisi sosio-ekonomis untuk lahan permukiman setiap waktu yang berbeda dan tempat yang berbeda, akan berbeda pula kesesuaiannya.

Kedua, adalah penggunaan satuan analisis administratif, berbeda dengan penggunaan satuan analisis lahan secara fisik, sehingga untuk menyesuaikan antara kesesuaian lahan secara fisik dengan kesesuaian lahan secara ekonomik masih memerlukan teknik (cara) tertentu dan harus hati-hati. Untuk tujuan evaluasi lahan permukiman secara umum, baik fisik maupun sosio-ekonomis, masalah batas satuan analisis ini sangat penting dan perlu diperhatikan. Satuan lahan fisik seyogyanya sebagai dasar analisis, baru diikuti satuan administratif. Dalam cara penyesuaian batas tersebut didasarkan pada prinsip dominasi, dimana luasan unit admistratif terbesar mewakili konndisi sosio-ekonomik dalam luasan unit lahan.

Ketiga, penggunaan tinggi rendahnya angka skor total belum tentu semakin tinggi skornya harus dinilai semakin baik. Baik atau tidaknya, penting atau tidaknya suatu keadaan yang ditunjukkan oleh angka skor total, bergantung pada tujuan analisis, dan tujuan evaluasi. Contoh di atas menunjukkan, semakin tinggi skor total sosio-ekonomis semakin rendah prioritas pengembangan permukiman. Namun jika tujuan analisis atau evaluasi untuk penentuan penataan ulang atau pengelolaan daerahdaerah yang telah padat dihuni, tentu- 
Tabel 3. Rumus Keseuaian Sosio-ekonomi untuk Pengembangan Lahan Permukiman

\begin{tabular}{|l|l|c||}
\hline Kelas & \multicolumn{1}{|c|}{ Kesesuaian } & \multicolumn{1}{|c|}{ Rumus } \\
\hline \hline I & Permukiman desa sangat sesuai dikembangkan & $<X_{M I N}+1 I$ \\
II & Permukiman desa sesuai dikembangkan & $X_{M I N}+1 I-<X_{M I N}+2 I$ \\
III & Permukiman desa cukup sesuai dikembangkan & $X_{M I N}+2 I-<X_{M I N}+3 I$ \\
IV & Permukiman desa tidak sesuai dikembangkan & $X_{M I N}+3 I-<X_{M I N}+4 I$ \\
V & Permukiman desa sangat tidak sesuai dikem- & $\geq X_{M I N}+4 I$ \\
\hline
\end{tabular}

Tabel 4. Kesesuaian Sosio-ekonomi untuk Pengembangan Lahan Permukiman Desa Kabupaten Kulonprogo

\begin{tabular}{|l|l|c|}
\hline Kelas & \multicolumn{1}{|c|}{ Kesesuaian } & Batas Nilai \\
\hline \hline I & Permukiman desa sangat sesuai dikembangkan & $<49,6$ \\
II & Permukiman desa sesuai dikembangkan & $49,6-<57,2$ \\
III & Permukiman desa cukup sesuai dikembangkan & $57,2-<64,8$ \\
IV & Permukiman desa tidak sesuai dikembangkan & $64,8-<72,4$ \\
V & Permukiman desa sangat tidak sesuai dikem- & $\geq 72,4$ \\
\hline
\end{tabular}


Tabel 5. Nilaj (Skor) Sosio-ekonomi Desa-desa di Kabupaten Kulonprogo

\begin{tabular}{|c|c|c|c|c|c|c|}
\hline \multirow{2}{*}{$\begin{array}{c}\text { NAMA KECAMATAN DAN } \\
\text { DESA }\end{array}$} & \multicolumn{4}{|c|}{ NILAI SKOR } & \multirow{2}{*}{$\begin{array}{l}\text { Rera- } \\
\text { ta } \\
\text { Skor }\end{array}$} & \multirow{2}{*}{$\begin{array}{l}\text { Kelas } \\
\text { Kese- } \\
\text { suaian }\end{array}$} \\
\hline & PD & PL & $\mathrm{KP}$ & $\mathrm{Jm}$ & & \\
\hline $\begin{array}{l}\text { 1. KECAMATAN TEMON } \\
\text { 1. Temon Kulon } \\
\text { 2. Sindutan } \\
\text { 3. Jangkaran } \\
\text { 4. Demen } \\
\text { 5. Janten } \\
\text { 6. Glagah } \\
\text { 7. Palihan } \\
\text { 8. Kulur } \\
\text { 9. Plumbon } \\
\text { 10. Kalidengen } \\
\text { 11. Temon Wetan } \\
\text { 12. Kaligintung } \\
\text { 13. Kedundang } \\
\text { 14. Kebonrejo } \\
\text { 15. Karangwuluh }\end{array}$ & $\begin{array}{l}21 \\
14 \\
18 \\
13 \\
13 \\
16 \\
17 \\
13 \\
13 \\
12 \\
17 \\
13 \\
13 \\
12 \\
13\end{array}$ & $\begin{array}{l}18 \\
19 \\
19 \\
22 \\
22 \\
22 \\
21 \\
18 \\
18 \\
17 \\
19 \\
19 \\
19 \\
19 \\
18\end{array}$ & $\begin{array}{l}27 \\
31 \\
26 \\
27 \\
27 \\
23 \\
20 \\
26 \\
25 \\
27 \\
20 \\
23 \\
22 \\
20 \\
19\end{array}$ & $\begin{array}{r}87.1 \\
66 \\
64 \\
63 \\
62 \\
62 \\
61 \\
58 \\
57 \\
56 \\
56 \\
56 \\
55 \\
54 \\
51 \\
50\end{array}$ & 58 & $\begin{array}{l}\text { II I I } \\
\text { IV } \\
\text { II I } \\
\text { II I } \\
\text { I. I I } \\
\text { I I I } \\
\text { III } \\
\text { II I } \\
\text { II } \\
\text { II } \\
\text { II } \\
\text { II } \\
\text { II } \\
\text { II } \\
\text { II } \\
\text { II }\end{array}$ \\
\hline $\begin{array}{l}\text { 2. KECAMATAN WATES } \\
\text { 16. Wates } \\
\text { 17. Bendungan } \\
\text { 18. Ciripeni } \\
\text { 19. Ngestiharjo } \\
\text { 20. Triharjo } \\
\text { 21. Kulwaru } \\
\text { 22. Sogan } \\
\text { 23. Karangwuni }\end{array}$ & $\begin{array}{l}29 \\
22 \\
16 \\
12 \\
15 \\
11 \\
14 \\
12\end{array}$ & $\begin{array}{l}22 \\
21 \\
21 \\
20 \\
19 \\
19 \\
21 \\
19\end{array}$ & $\begin{array}{l}29 \\
21 \\
20 \\
24 \\
20 \\
23 \\
18 \\
22\end{array}$ & $\begin{array}{r}470 \\
80 \\
64 \\
57 \\
56 \\
54 \\
53 \\
53 \\
53\end{array}$ & 59 & $\begin{array}{c}\text { I I I } \\
\text { V } \\
\text { I I I } \\
\text { I I } \\
\text { I I } \\
\text { I I } \\
\text { I I } \\
\text { I I } \\
\text { I I }\end{array}$ \\
\hline $\begin{array}{l}\text { 3. KECAMATAN PANJATAN } \\
\text { 24. Panjatan } \\
25 . \text { P leret. } \\
26 . \text { Bugel } \\
\text { 27. Cotakan } \\
\text { 28. Tayuban } \\
\text { 29. Bojong } \\
\text { 30. Cerme } \\
\text { 31. Krembangan } \\
\text { 32. Garongan } \\
\text { 33. Depok } \\
\text { 34. Kanoman }\end{array}$ & $\begin{array}{l}22 \\
18 \\
14 \\
18 \\
14 \\
13 \\
13 \\
13 \\
14 \\
14 \\
12\end{array}$ & $\begin{array}{l}20 \\
19 \\
19 \\
19 \\
19 \\
19 \\
18 \\
17 \\
19 \\
19 \\
19\end{array}$ & $\begin{array}{l}23 \\
27 \\
29 \\
24 \\
28 \\
28 \\
25 \\
24 \\
21 \\
21 \\
22\end{array}$ & $\begin{array}{r}644 \\
65 \\
64 \\
62 \\
61 \\
61 \\
60 \\
56 \\
54 \\
54 \\
54 \\
53\end{array}$ & 59 & $\begin{array}{l}\text { III } \\
\text { IV } \\
\text { I I I } \\
\text { III } \\
\text { II I } \\
\text { II I } \\
\text { I I I } \\
\text { I I } \\
\text { I I } \\
\text { II } \\
\text { I I } \\
\text { II }\end{array}$ \\
\hline
\end{tabular}

ESL_PER-14 


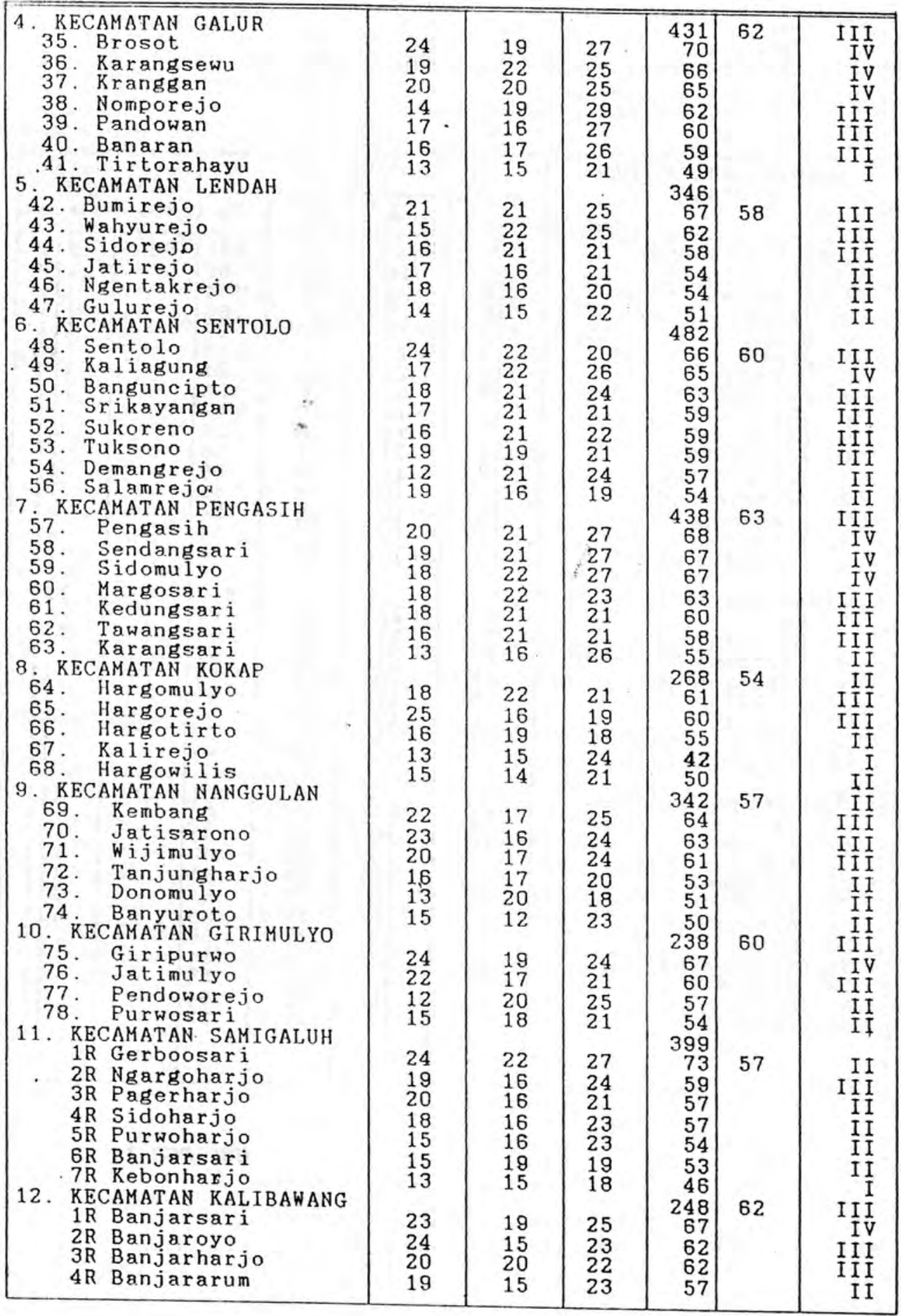


demikian, perhatian terhadap hasil analisis aspek fisik lahan untuk pertimbangan perlu ditekankan.

Sebagai contoh, misalnya dalam satu satuan lahan F1-A-P adalah tanggul alam dengan tanah aluvial, dari aspek fisik untuk permukiman sangat sesuai (Kelas I). Namun dari aspek sosio-ekonomik, unit lahan tersebut mencakup 5 desa misalnya 3 desa secara utuh yang keseluruhannya tidak sesuai untuk pengembangan, sedangkan 2 desa lainnya hanya tercakup masing-masing kurang dari setengah, tetapi sangat sesuai untuk dikembangkan. Dalam hal ini pertimbangan sosio-ekonomis 3 desa tersebut yang harus digunakan dalam mendukung hasil evaluasi lahan secara fisik. Tentunya untuk menentukan prioritas pengembangan, unit lahan ini tidak direkomendasikan lagi, dengan alasan secara fisik sangat layak, ditam- bah lagi tidak sangat layak dari aspek sosio-ekonomis, yang berarti baik poten$s i$, lingkungan perumahan, maupun kondisi demografisnya sangat sesuai.

\section{PENUTUP}

Faktor-faktor sosio-ekonomis yang dapat digunakan untuk mengevaluasi lahan permukiman, pada dasarnya tidak terbatas hanya pada ukuran variabel seperti telah dikemukakan. Dapat saja dilakukan modifikasi untuk merinci atau menggeneralisasi ke ukuran yang lebih makro. Tetapi penting diperhatikan, bahwa evaluasi lahan permukiman untuk tujuan pengembangan dan pengelolaan lingkungan permukiman seyogyanya dilaksanakan secara terpadu baik dari aspek fisik maupun aspek manusia.

\section{REFERENSI}

Anonim, Guidelines for Rural Centre Planning, United Nations, Economic and Social Commiission for Asia and The Pacific, New York, 1979.

Berg, Van den, Anticipating Urban Growth in Africa: Land use and Landa Values in th Rurban Fringe of Lusaka, Zambia, Zambia Geographical Association, Lusaka, 1984

Brian, C.R., et. al., The Ciity's Countryside: Land and Its Management in the Ruural-Urban Fringe, Longman, London, 1982.

Hilhorst, JG.M, Regionla Planning: A System Approach, Rotterdam University Press, Rotterdam, 1971.

Nelson, de Von, Guidelines for Rural Lannd Use Planning in Developing Countries, FAO, 1986.

Ngadiono dan Bedjo Suwandhi. 1979. Konsep Pemikiran Metoda Standarisasi Klasifikasi Penggunaan lahan. Bogor: Pusat Studi Pengelolaan Sumberdaya dan Lingkungan IPB.

Rondinelli, Dennis A, Applied methods Of Regional Analysis, The spatial Dimensions Of Devolopment Policy, Westview Press, Boulder Colorado, 1985 Sitorus, R.P. Santun. 1985. evaluasi Sumberdaya Lahan. Bandung: Tarsito. 
Su Ritohardoyo, Beberapa Dasar Klasifikasi Permukiman dan Pola Permukiman, Fakultas Geografi Universitas Gadjah Mada, Yogyakarta, 1989.

Zonneveld, I.S. 1969. Land Evaluation. ITC Lecture Note. Ennschede: ITC

Yunus, Hadi Sabari, Geografi Permukiman dan Beberapa Permasalahan Permukimman di Indonesia, Fakultas Geografi Universitas Gadjah Mada, Yogyakarta, 1987 